\title{
Research on Inclusive Responsibility of Rural Financial Institutions of Hunanprovince
}

\author{
Yeyun Liu \\ Economic College of Hunan Agrculture University
}

\author{
Mingxian Li \\ Economic College of Hunan Agriculture University
}

\begin{abstract}
Rural financial institutions are the key to the rural financial business and services. As the mainstay of rural finance and the best link of "three agriculture", the role of rural financial institutions play a direct impact on the development of rural economy and improvement of farmers' life, and affect various undertakings of the socialist new rural construction. Today, the implementation of corporate social responsibility is increasingly valued. The uniqueness of rural financial institutions requirement to practice inclusive responsibility to gain profits, common development of farmers and rural society when they peruse the corporate profits. Rural financial institutions in the process of practice inclusive responsibility should learn experience, so as to better serve the rural construction.
\end{abstract}

Keywords: Ruralfinancial; institutions Practice; Inclusive responsibility

\section{INTRODUCTION}

Being a significant component of rural financial system, financial institutions in countryside have been playing a crucial role in providing services like saving, loans and financing. The process of rural financial system reform requires advanced construction of rural financial system, therefore, rural financial institutions should devote themselves to enhance management system and promote the change of business philosophy.

Of the most important is that rural financial institutions are supposed to realize the meaning of fulfilling social responsibility and regard the responsibility as a standard of self-improvement as well as a critical part of enterprise culture construction which corporate leaders can exploit to guide practice, strengthen the connection with stakeholders and meet their dimensional demands. It is imperative for new rural financial organizations to have a better knowledge of "agriculture" practically and philosophically. Only by learning from practice can we adjust operating strategies, sort out perplexed problems and benefit every party in the end.

\section{THE NECESSITY OF PERFORMING INCLUSIVE RESPONSIBILITY}

Takingthe internal and external environments in to consideration, there is a inevitability for rural financial institutions to perform inclusive responsibility.

A. As the major organizations providing financial service in rural areas, rural financial institutions ensure the basic requirements from their clienteles, at the same time, provide essential fiscal backing for local economic development.
The party and government attach great importance to the construction of new socialist countryside, and the infrastructure construction in rural areas cannot live without the construction of rural financial institutions. It is the financial service beneficial to primary farmers and common enterprise that will be conductive to stimulate rural economy and bring in considerable benefits.

$B$. In order to solve the contradiction between supply and demand of rural finance, it is necessary to choose to practice inclusive responsibility in rural financial institutions'. The rural financial market demand include farmers' deposit and loan needs, rural business cash flow, the construction in countryside and so on, however, rural financial institutions in countryside is rarely, its only have Agricultural Bank, Rural Credit Cooperatives, Agricultural Development Bank etc, this kind of serious contradiction between supply and demand requires carrying out inclusive responsibility of the rural financial institutions, promoting the healthy development of rural finance.

C. With the purpose of improve the rural financial institutions' competitive, it is the inevitable need to practice inclusive responsibility. From radiation scope, the commercial banks mostly provide financial service to urban market, such as the urban population, large enterprises as well as national and government, while rural financial institutions mostly provide financial service to a relatively fixed group, which are include agriculture, countryside and farmers. From the point of business scope, commercial banks not only operate cash business for personal and units, but also provide various types of project support and financial services for the development of the state and companies. While rural financial institutions as a result of its constraints of service object, its scope of business is only concentrated in provide personal financial services and corporate loans for farmers and micro-enterprises, as well as implement all rural grassroots economic and financial policies of the state. In order to improve their own competitive, rural financial institutions should do a lot of things, including innovate financial services, broaden the service object, strengthen the marketing and so on, all of these objectives can be done by practice inclusive responsibility.

\section{CURRENT Situation Of The RURAL FINANCIAL INSTITUTIONS PRACTICE INCLUSIVE RESPONSIBILITY}

\author{
D. Connotation of Inclusive Responsibility in China's \\ Rural Financial Institutions \\ "GSP-financial" also called inclusive financial, it refers
}


to a country's financial system can be effective in all directions to benefit all social strata and groups. Within the system, all the people, especially the rural areas which are ignored by the traditional financial, urban and rural low-income groups, micro and small enterprises can enjoy to effective financial services. Formal financial institutions in the past unwilling to provide credit to poor lending practices because of their loan are small number, high-risk and poor reputation, however, GSP-financial is more emphasis on a moral and social equity. Through the improvement of the financial system, it inclusion of the potential for sustainable development of micro-credit in formal financial system, excavation of vulnerable groups not covered by the traditional financial and help them into the financial system and provide them with equal right to enjoy modern financial services. All of this are able to bring the social justice in the field of financial services, and bring everyone into the economic growth path, and ultimately improve the welfare of society as a whole. Micro-credit is the heart of GSP-financial, it refer to micro aspect, middle aspect, and macro aspect. GSP-financial not only focuses its attention on the social responsibility, but also actively seeks financial sustainability. In short, GSP- financial is aimed at provide financial system for all persons in a society, especially the poor and low-income people.

\section{E. Current Situation of the Rural Financial Institutions} Practice Inclusive Responsibility

Firstly, rural financial institutions build the infrastructure of rural financial, for the implementation of inclusive responsibility to establish a foundation. And continue to strengthen the rural financial service network and service channels of the building. The "three agriculture" financial service station as the supply of Incase channels, such as, in rural credit cooperatives to establish site extended financial services; in areas covered less network launched mobile services and car banking services. At the same time, to widen the card using channels, increase the number of self-help equipment in the rural areas, such as ATM, transfer the phone, and to develop modern service methods, such as telephone banking, Internet banking, SMS, etc. Until June 2012, the rural credit cooperatives in Hunan province is expanded to aid farmers withdrawal service point 340 , recommend to union pay business company to expand service point 1000, withdrawal transactions happened in all 5487, transaction value of 1.157 million Yuan.

Secondly, aimed at the main service groups to expand the scope of the services and carry out inclusive concept. For farmers, agricultural enterprises, small and medium-sized enterprise loans give preferential, reduced the enterprise and farmer interest burden. And try to provide deep, close and personal financial services for the" three agriculture" 。 In recent years, the rural financial institutions for personal and business loan customers present the trend of increased year by year, has laid a good foundation for inclusive responsibility.

Finally, the innovation of financial service, For example, positive Innovation mode of guarantee and credit business, set up third party supervision chattel pledge loan and community credit loans, promote farmers group lending and farmers' professional co-operatives loans, "Gold farmers" loans, "new life movement" personal consumption loans, self-help circulating consumer loans and other credit products, enhance market competition ability. In 2003, 2004, 2005, 2006, 2007, 2008, 2009, 2010, the loan balance of agricultural development bank branch in Hunan province respectively 30.243 billion Yuan, 31.324 billion Yuan ,31.324 billion Yuan, 36.735 billion Yuan, 457, 5.8 billion Yuan, 552.73 billion Yuan, 597.23 billion Yuan, 64.754 billion Yuan. It's turnover in a rising trend. From 2008 to 2010, the innovation work of the rural financial product and service has been extended to the province's 85 counties (city).the agricultural loan of bank financial institutions in Hunan got rapidly growth. It's total of 311 billion Yuan, increasing $19.6 \%$ to 51.57 billion Yuan in 2010.

Rural financial institutions have a success in rural areas of financial services. Due to practicing inclusive responsibility in its infancy, there are still some shortcomings.

1) Scope of inclusive responsibility needs to be expanded.

Rural financial institutions' main service scope is to provide small loans for farmers, carry out all construction in rural areas of the state, and to provide financial services in rural areas for part of the business in micro or small businesses. But the vast rural market has not fully open, rural financial institutions should make full use of farmers' awareness of self-employment to receive support, so as to achieve a win-win situation; To carry out national policy in financial service aspects, countries should tilt to the construction projects which related to people's livelihood and practice inclusive responsibility.According to the survey, farmer's loan demand is stronger, and at the end of $2009,77.6 \%$ of the farmers need to bank loans, the proportion will rise $10 \%$ by 2010 . Currently, the bank mainly provides small credit to farmers (generally the amount is less than 10000 Yuan, the maximum not more than 20000 Yuan). In the loan application of the peasant household, only $33.5 \%$ of the farmers demand for credit, have been fully satisfied, $48.2 \%$ of farmers get some partly loan.

\section{2) Inclusive responsibility remains to be improved.}

Rural financial institutions basically meet the needs of the rural marketin financial services infrastructure of inclusiveresponsibility. However, we ignore the propaganda of financial theory and financial knowledge in rural areas. Furthermore, Due to the oneness of rural financial tools, the masses of rural are less involved in financing, which brings some difficulties in practicing inclusive responsibility. Compared with the urban commercial Banks, rural financial institutions also have relatively little input in after-sales service.

3) Operation mechanism and management system needs to be optimized.

In the rural market, rural financial institutions have more credit limitation and the process is more complicated. Credit risk control ability is weak result in individual credit 
threshold is too high which impact lending and the farmers' borrowing enthusiasm. At the same time, credit of grassroots enterprise lack of effective risk evaluation mechanism, therefore, the support of enterprise development is very limited.

\section{The SugGeStion FOR CHINA's RURAL FINANCIAL INSTITUTIONS PRACTICE INCLUSIVE RESPONSIBILITY}

In order to make the rural financial institutions to better practice inclusive responsibility, the country, the rural financial institutions and the "three rural" should cooperate with each other; and play an important role.

A. To Strengthen the Legislation of Gsp Financial.

The state should define the rural GSP financial from the macro and build the rural GSP financial system. The rural GSP--financial institutions should make clear the responsibility of the rural financial. And the rural financial institutions have laws to practice.

\section{B. To Strengthen the Support for Rural Financial Institutions.}

Countries and superior departments of rural financial institutions should give on fiscal policy tilt, and improve the relevant amount proportion of agricultural loans. Tax authorities should relief income tax in rural financial institutions and arouse the enthusiasm of practicing inclusive responsibility.

\section{To Build the Protection Mechanism Matched with Gsp-Financial.}

Rural financial institutions should be aimed at the particularity of its market to ensure the diversity of financial instruments, and make sure rural masses and rural enterprises toconveniently accept financial services in suitable ways. To optimize the service level from service processing, service effect and other aspects. And let more mass join in the rural finance. Strengthen the propaganda of rural masses of financial management consciousness and teach them more convenient way of finance.

\section{Build a Scientific Operation and Management Mechanism.}

Rural financial institutions in the process of practicing inclusive responsibility should establish scientific and reasonable credit risk evaluation and control mechanism, so that we can ease restrictions on agriculture and the rural individuals and enterprise credit. And we should simplify the credit process, arouse the enthusiasm of peasant household and enterprise to make full use of the preferential policies of rural financial institutions to do business and promote rural economic development.

\section{CONCLUSION}

In the critical period of the state attaches great importance to the new rural socialist construction, rural financial institutions plays an important role in the implementation of national policies, promotion the construction of rural and improvement the rural people's livelihood. Rural financial institutions only practice social inclusive responsibility; we can strengthen the contact with rural masses, rural enterprises and the rural economy. We also can promote the development of countryside and the level of people's livelihood and obtains the rural financial institutions and the "three rural" win-win.

\section{REFERENCES}

[1] Eremy Moon, 2004. Government as a Driver of Corporate Social Responsibility.ICCSR Research Paper Series.

[2] Geoffrey Heal, 2004. Corporate Social Responsibility - An Economic and Financial Framework. Annual Conference of the Monte Paschi Vita.

[3] ing He, Rui Zhang, 2010. Speed up the construction of inclusive rural financial system of demand leading. Journal of Yunnan Finance \&Economics University: 01:91-92.

[4] Huaiming Nai, 2009. Rural credit cooperatives practicing social responsibility and thinking. Journal of Fujian Financial: 12:40-43.

[5] Mingli Liang, 2011. Research on construction of rural inclusive financial system in our country. The paper of master's degree of Shandong school of economics and finance institute.

[6] Ximei Li, 2007. Research on China's rural financial institutions practice a system of corporate social responsibility. Journal of Finance and Economy: 08:52-58.

[7] Ximei Li\&Sumei Lin\&Yinfang Chen, 2009. China's new rural financial institution to fulfill its social responsibility. Journal of Economy and Management: 06:31-33.

[8] Quan Wen, 2011. To develop microcredit and Promote GSP-financial services. Journal of Economic Vision: 10:123-125 